\title{
Energy-based performance analysis of a double pass solar air collector integrated to triangular shaped fins
}

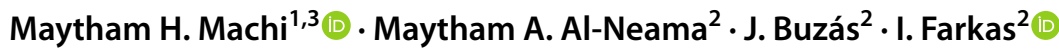

Received: 23 March 2021 / Accepted: 22 August 2021 / Published online: 31 August 2021

(c) The Author(s) 2021

\begin{abstract}
In this paper, the performance of a double pass solar air collector with triangular integrated fins was investigated experimentally at Hungarian University of Agriculture and Life Sciences in Gödölló, Hungary. The focus of this research is on energy-based performance evaluation. The thermal efficiency of the collector has been compared by testing two collectors that had the same design, with and without fins. The effect of the collector's air mass flow rate on thermal performance was investigated under various environmental situations. The results revealed that the temperature difference is always higher through the finned collector and the higher variation temperature between the inlet and outlet temperature leads to higher useful heat. The daily thermal efficiency of the finned collector was $56.57 \%, 59.41 \%$, and $61.42 \%$, while for the un-finned collector was $51.04 \%, 53.28 \%$, and $57.08 \%$ for the mass flow rate $0.0081,0.0101$, and $0.0121 \mathrm{~kg} / \mathrm{s}$. The finned double pass solar air collector improved the thermal efficiency by $4.3-6.1 \%$ over the un-finned one. The efficiency of the finned collector is always higher than the un-finned one regardless of the mass flow rate. The presence of the fins to the top air channels significantly increases collector efficiency, owing to the increased absorbing surface area, which is responsible for increasing the internal thermal convective exchanges. Moreover, it creates a turbulence airflow, meaning that the air will be in good contact with the absorber plate and penetrate all regions, reducing the dead zones contributing to increased heat transfer.
\end{abstract}

Keywords Solar energy $\cdot$ Collector construction $\cdot$ Fined absorber $\cdot$ Thermal efficiency

\section{Introduction}

The incredibly increasing world population gives rise to increases in energy demands, which leads to an increase in the usage of conventional fuels. The limited sources of traditional fuels and environmental protection issues, and global warming, are becoming a pressing problem that needs to be outlined. These concerns drew the attention of the researchers to find renewable resources considered a promising solution to global warming and a way for keeping sustainable growth for human beings [1]. A lot of alternative energy

I. Farkas

farkas.istvan@uni-mate.hu

1 Doctoral School of Mechanical Engineering, Hungarian University of Agriculture and Life Sciences, Gödöllő, Hungary

2 Institute of Technology, Hungarian University of Agriculture and Life Sciences, Gödöllő, Hungary

3 Department of Mechanical Engineering, Faculty of Engineering, University of Kufa, Najaf, Iraq sources that produce energy, again and again, can be used instead of fossil fuels such as biomass, wind, geothermal, hydropower, and solar energy. Efficient utilization of renewable energy resources depends on economic, environmental, and safety considerations [2].

Solar energy is the most massive renewable energy source, representing the primary source of energy to the earth. Solar energy can be utilized by using several technologies that work as a converter through converting the solar radiation to usable electricity or heat using photovoltaic (PV) and thermal systems. Photovoltaic cells produce electricity directly, while solar thermal systems produce heat for buildings, industrial processes, or domestic hot water. The primary device for collecting solar energy, known as a solar energy collector, should be present in any solar thermal system. It works as a unique heat exchanger that converts solar radiation energy to heat energy stored inside a transport fluid (air, water, or oil) [3]. One of the most potential solar energy applications is the supply of hot air through the solar air collector to dry agricultural or marine products 
and for building heating to preserve a pleasant atmosphere, particularly during the winter season [4].

The flat plate solar air collectors are simple in terms of construction and operation with low fabrication costs. It has many advantages over liquid solar collectors, such as corrosion, boiling, leakage, and freezing problems. The main disadvantage of the solar air collectors is the low heat transfer rates between the collector absorber and the air passed through. Moreover, the collector's thermal efficiency is low because of the poor thermal conductivity and low heat capacity of the air [5]. Many researchers are trying to make different modifications to increase the heat transfer rate inside the collectors between the absorbing surface and flowing air. A theoretical and experimental investigation to improve the thermal performances of a solar air heater with rectangular plate fins inserted as a row perpendicular to the flowing air was conducted. It was concluded that the fins' existence increases the amount of useful heat gained from the solar collector [6]. The performance of solar air collectors with flat plate v-corrugated and finned absorber have been investigated experimentally and theoretically. The collectors tested in both single and double pass modes. The results showed that the v-groove collector being more efficient than the finned collector in both modes. The effect of using double pass mode was obvious on the efficiency of the flat plate collector and least on the v-grooved collector [7].

A theoretical model and experimental validation have been conducted for a dual pass solar collector with porous material inside the lower pass. The results showed that the outlet temperature was enhanced by using the porous material, which improves the system efficiency. It was concluded that the typical efficiency of such kind of collectors with the porous material is around $60-70 \%$ [8]. A dual pass solar air heater with fins in the lower channel had been studied experimentally. The study showed that the finned absorbing surface is $8 \%$ more efficient than the flat plate absorber. Moreover, the efficiency relies considerably on the airflow rate and the intensity of the solar radiation [9]. The performance of both single and dual pass solar air heater with an absorber made of steel wire mesh and longitudinal fins attached had been investigated experimentally. The results showed that the collector efficiency improved considerably with mesh as an absorber compared to the standard collector. Moreover, the thermal efficiency and temperature difference are more with the double- pass as compared with the single pass [10].

Also, experimental investigation results of a single pass solar air heater with and without using fins showed that the thermal efficiency affected significantly by changing the airflow rate, the solar radiation intensity, and the shape of the absorber [11]. The thermal efficiency of a two-pass solar air collector with two inlet ports was experimentally investigated with four different absorber plates under various mass flow rates within the upper and lower inlet ports. Smooth plate, pin finned, corrugated-perforated finned, and corrugated finned absorbers were tested. The results indicate that the absorber plate's temperature reduces with an increase in the upper air flow proportion for all absorber types. Also, improving heat transfer rate by using fins reduces the temperature of the absorber plate. The collector efficiency improves with the difference in the outlet-inlet temperature [12]. An investigation of dual pass solar air heaters with vertical and horizontal extended surfaces combined with a dryer active-air circulation has been studied experimentally. The test results showed that the daily efficiency increased by $10 \%$ when the fins direction changed from vertical to horizontal. Moreover, the effect of collector efficiency enhancement was very clear on the dryer by reducing the time to remove the dried product's water content [13].

Furthermore, the thermal efficiency of a double pass solar air collector was investigated experimentally. A semiempirical thermal model was created to explain its thermal behavior theoretically. The model can estimate the air temperature at the collector outlet from known values of the outside temperature and solar irradiance on the collector plane. The temperature difference between the inlet and the outlet reaches $40{ }^{\circ} \mathrm{C}$ at $0.020 \mathrm{~kg} / \mathrm{s}$. The average daily efficiency was found to be $42 \%$, with overall instantaneous efficiency of $50 \%$. The thermal efficiency reached $60 \%$ at a mass flow rate of $0.045 \mathrm{~kg} / \mathrm{s}$, and the mean outlet temperature is $46^{\circ} \mathrm{C}$. The experimental and theoretical models were found to be in good agreement [14]. Sudhakar et al. conducted an experimental investigation of a double pass solar air collector with a V-grooved absorber plate with pin fins. The results showed that the efficiency of the collector is strongly affected by the mass flow rate. The mean collector temperature raised by $12 \%$, and the temperature difference between outlet to inlet temperature reached $14.8^{\circ} \mathrm{C}[15]$.

Likewise, a mathematical evaluation for a multi-pass solar air heater with longitudinal fins was conducted. The study argued several parameters that affect the collector's thermal performance, namely the solar intensity, the airflow rate, and the inlet temperature. The solution of the mathematical model was conducted by using MATLAB. The result showed that the mass flow rate has a significant effect on the thermal efficiency and the collector's outlet temperature. The introduction of fins enhanced the thermal efficiency of both triple and double pass solar collector [16]. The performance of an offset finned solar air heater was investigated analytically with a parametric analysis to study the effect of modifying a structure and working parameters such as fin lengths, insulation content, and airflow rate on thermal and thermohydraulic efficiencies. Attaching offset fins below the absorber plate at a lower mass flow rate has been discovered to increase thermal and thermohydraulic efficiencies significantly. The peak percentage increase in thermal and 
thermohydraulic efficiencies was discovered to increase with a reduction in fin spacing and an increase in fin height [17].

This work investigates experimentally the performance of a double pass solar air collector with particular triangular shaped fins attached to the upper side of the absorber. The tests were carried out at the Solar Laboratory of the Hungarian University of Agriculture and Life Sciences under the conditions of Gödöllô city, Hungary. In previous works, many absorbers' configurations had been tested under the conditions of Gödöllo, but the new selected shape of fins has not been tested. Twin double pass flat plate solar air collectors with and without fins have been tested simultaneously, and the efficiency is compared on energy-based performance evaluation.

\section{Material and methods}

Two double pass solar air collectors with and without fins were tested at the same operating condition to achieve the purpose of this work. The collectors were produced practically with a modification made on one of the collectors by attaching triangular fins on the absorbing surface's upper face. The collector dimensions are 1250, 500, and $150 \mathrm{~mm}$ length, width, and height, respectively. The external case body was mainly made of wood due to its low-cost and weight, easy to fabricate, and has a low thermal conductivity, which makes it good insulation material. The absorber is made of (C 110) copper sheet with a thickness of $1.2 \mathrm{~mm}$ and $1218 \mathrm{~mm}$ by $462 \mathrm{~mm}$ dimensions. It was coated with black matt paint to decrease the heat loss by reflected wave radiation from the absorber plate.

The absorber of the first collector is a flat plate and contains no barriers or components of roughness (see Figs. 1 and 2). On the other hand, the second collector's absorber has triangular fins on the upper face of the absorbing surface to enhance the heat exchange rate by increasing the absorbing area, which causes an increase in collector thermal efficiency. The dimension of the fin is $40 \mathrm{~mm}$ in height, and the

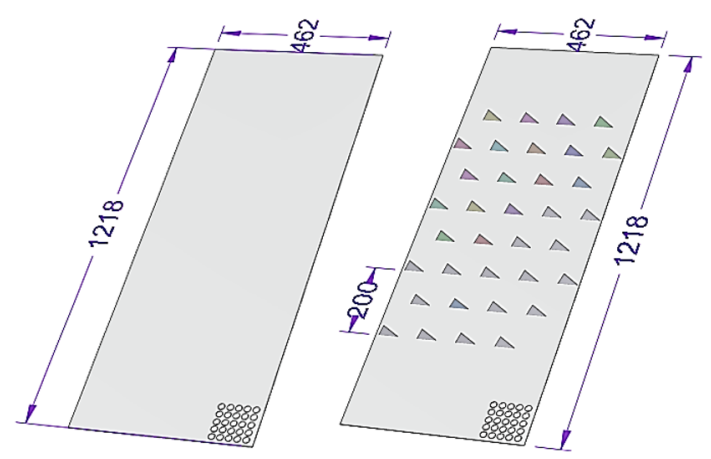

Fig. 1 Absorbing surface for the collectors

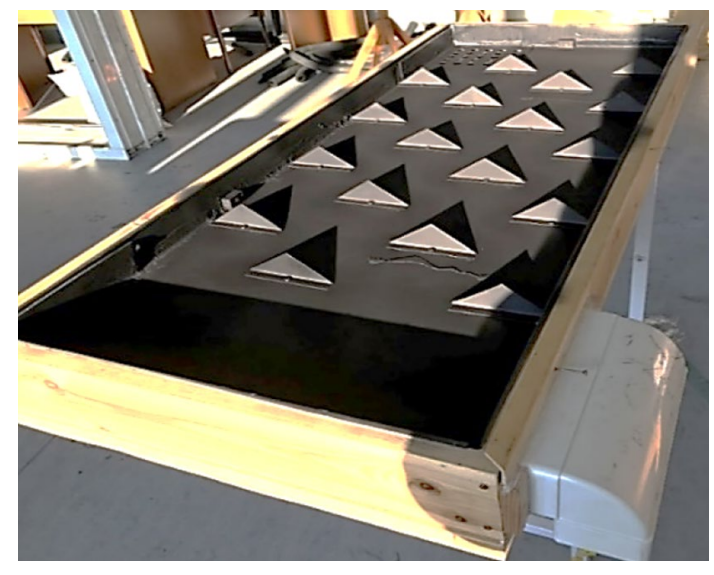

Fig. 2 Second absorber plate attached to the triangular fins

base is $100 \mathrm{~mm}$. The fins' total number is 18 with a $200 \mathrm{~mm}$ distance between every two fins in the same line, and it is fixed in a staggered. A transparent plastic cover is used to reduce convection losses from the absorber plate by keeping the air passing along between the cover and absorber. The cover comprises high-quality, extremely tough polystyrene sheets with $4 \mathrm{~mm}$ thickness. The height between the cover and the absorber is $57.5 \mathrm{~mm}$ forming the first pass, and the second pass is $35 \mathrm{~mm}$ high. An expanded polystyrene material with $20 \mathrm{~mm}$ thickness was used as an insolation layer in the back of the collector to minimize the heat loss. The air is circulated inside each collector using one $\times 12 \mathrm{~V}$ InLine Bilge air blower with a high flow capacity of 270 CFM (Cubic Feet per minute). Two laboratory power supply Voltcraft (PS 1440, 0-36 V/DC, 0.01-40 A) and (VLP-1602, $2 \mathrm{~A} 6 \mathrm{~V})$ were used to supply and monitor the power of the blower and to regulate the outlet voltage to adjust the velocity of the fan blower.

The air flow velocity through the inlet port was measured by using anemometer made by PEAK METER $®$ model MS6252A with 2\% accuracy. The temperature is measured using five K-type thermocouples where two of them were placed on the absorber plate, and the rest were placed in the inlet, outlet, and the second pass inlet orifices. Before being installed, the thermocouples were joined with solders, calibrated, and checked. It was connected to a digital thermocouple thermometer with $\pm 1{ }^{\circ} \mathrm{C}$ accuracy. The solar radiation intensity is measured by using digital solar meter made by KIMO model SL-200 with 5\% accuracy. The constructed solar air collectors were fixed at the solar laboratory of the Institute of Technology, Hungarian University of Agriculture and Life Sciences, Gödöllő, and oriented facing south and tilted at $45^{\circ}$ to the horizontal for Budapest city (Budapest $\left.47.5^{\circ} \mathrm{N}, 19.05^{\circ} \mathrm{E}\right)$.

The air will move through the baffles to ensure a good air distribution under the absorber plates, create the turbulence, 
and reduce the dead zones. The absorber plate is placed over the baffles to be the limit between the upper and lower air channel as shown in Fig. 3. Several screws tie all the collector components together securely, with an adhesive substance has been used to avoid any air leakage, as air leaks will affect the collector's performance and decrease efficiency.

In general, the performance of any solar collector is compared by using the term thermal efficiency. It is the primary requirement for the forecasting of the collector performance [18]. The efficiency collectors depend on several parameters such as optical, thermal properties, and the shape of the absorbing surface. Moreover, ambient temperature and wind speed, the solar radiation intensity on the collector plate, the angle of incidence of solar radiation, the inclination of the collector, and mass flow rate of the working fluid.

The thermal efficiency of a solar collector is the ratio between the useful heat of a given time divided by the incident solar radiation of the same period [19]:

$\eta=\frac{Q_{u}}{Q_{i}}$

where $Q_{u}$ is the accumulated useful energy extracted from the collector during the working period which can be calculated from Eq. 2, and $Q_{i}$ is the solar energy harvested by the collector absorber plate and it is given by Eq. 4 .

$Q_{u}=\dot{m} C_{P}\left(T_{\mathrm{o}}-T_{i}\right)$,

where

$C_{p}$ : the specific heat capacity of air,

$T_{\mathrm{o}}$ and $T_{\mathrm{i}}$ : the collector outlet and inlet temperature, respectively.

$\dot{m}$ : the mass flow rate circulated inside the collector in $\mathrm{kg} / \mathrm{s}$, which can be determined in Eq. 3:

$\dot{m}=\rho V A_{d}$

where:

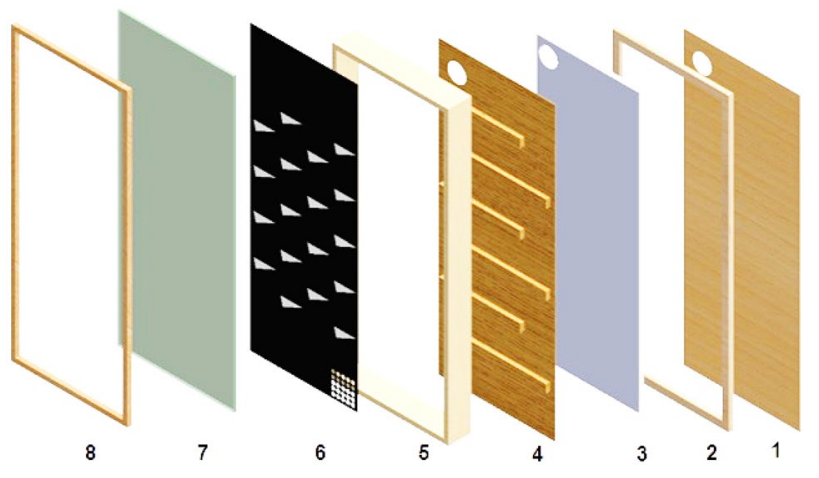

Fig. 3 Collector component arrangement: 1. back cover 2. wood frame 3. insolation 4. wood cover with baffles 5 . wood walls 6 . absorbing surface 7. plastic cover 8 . wood strips $\rho:$ air density $\left(\mathrm{kg} / \mathrm{m}^{3}\right)$,

$V$ : average air velocity $(\mathrm{m} / \mathrm{s})$,

$A_{\mathrm{d}}$ : the cross-section area of the air duct $\left(\mathrm{m}^{2}\right)$.

Finally, the harvested solar energy $Q_{i}$ is coming from:

$Q_{i}=I A_{c,}$

where

$I$ : solar radiation intensity $\left(\mathrm{W} / \mathrm{m}^{2}\right)$,

$A_{c}$ : the absorbing surface area $\left(\mathrm{m}^{2}\right)$.

So, the final form of the collector instantaneous efficiency can be as following:

$\eta=\frac{\dot{m} C p\left(T_{\mathrm{o}}-T_{\mathrm{i}}\right)}{I A}$

The daily solar radiation and useful daily energy were calculated using the trapezoidal numerical integration method. It can be described as follows [20]:

$Q_{u}=\int_{t 1}^{t 2} q(t) d t=\frac{h}{2}\left[Q_{u 1}+2 Q_{u 2}+2 Q_{u 3}+\ldots+Q_{u n}\right]$

$I=\int_{t 1}^{t 2} I(t) d t=\frac{h}{2}\left[I_{1}+2 I_{2}+2 I_{3}+\ldots+I_{n}\right]$

where

$h$ : time increment in (s),

$q(t)$ : the function of useful energy to the time,

$q(t)$ : the function of solar radiation intensity to the time, $t_{1}$ and $t_{2}$ : the initial and final time.

The uncertainties of measurement can propagate due to several sources such as the instrument that have been used in the experiment, the environmental condition, operator skills, and test preparation. It is beneficial to explain measurement uncertainty and estimate how different uncertainties developed into the measured result [21].

Based on Eq. 5, with considering the $A_{c}$ and $C_{p}$ are constant, the fractional thermal efficiency uncertainty and all the contributed variables and their uncertainties are presented in Eq. 8.

$\frac{\omega \eta}{\eta}=\sqrt{\left[\left(\frac{\omega \dot{m}}{\dot{m}}\right)^{2}+\left(\frac{\omega \Delta T}{\Delta T}\right)^{2}+\left(\frac{\omega I}{I}\right)^{2}\right]}$

For each collector, the mean value of all variables for each day was calculated individually. Then, for all the days combined, the mean value (of the variable mean values) was calculated and used to measure the fractional uncertainty [10]. For all days combined, measured mean values for the experiments $\left(T_{\mathrm{i}}, T_{\mathrm{o}}, \Delta T, I\right.$, and $\left.\eta\right)$ were $22.78{ }^{\circ} \mathrm{C}, 51.81{ }^{\circ} \mathrm{C}, 29.03{ }^{\circ} \mathrm{C}, 882.87 \mathrm{~W} / \mathrm{m}^{2}$, and $56.03 \%$, respectively. The final uncertainty of the thermal efficiency was 0.00654 . 


\section{Results and discussion}

The results of the experiments collected by testing two solar air collectors at the same time under the same working condition (see Fig. 4). The inlet, outlet, inlet of second pass inlet, and the absorber temperature, as well as the solar radiation intensity, have been obtained during the day time. The amount of useful heat gained and the thermal efficiency for each collector has been calculated. A comparison between the experimental results of the two collectors has been conducted.

The experiments were conducted on days with clear sky conditions and low wind speed. The experiments carried out on the 8th, 9th, and 12th of April 2018, under three different mass flow rates $(0.0081,0.0101$, and $0.0121 \mathrm{~kg} / \mathrm{s})$, which are in the recommended range mentioned in literature for such kinds of solar collectors. The measurement results were recorded manually for every five minutes between 9:00 and 15:00. The air density $1.22 \mathrm{~kg} / \mathrm{m}^{3}$, the specific heat at constant pressure $1006 \mathrm{~J} / \mathrm{kg} \mathrm{K}$. The diameter of the duct which circulated the air was $65 \mathrm{~mm}$. The measured data such as temperature, airflow speed, and solar radiation are obtained using well-calibrated instruments.

Figure 5a, b, c shows the inlet and the outlet temperature of the collector versus time under each mass flow rate. The outlet temperature increases with solar intensity until a maximum value and then decreases simulating the solar intensity curve. On the other hand, the outlet temperature has a reverse relationship with the airflow rate, which rises as the flow rate is reduced and vice versa. For the mass flow rate of $0.0081 \mathrm{~kg} / \mathrm{s}$, the outlet temperature reaches a maximum value of $68.1{ }^{\circ} \mathrm{C}$ for the finned collector with more than $4{ }^{\circ} \mathrm{C}$ temperature higher compared to the un-finned collector, which was $64{ }^{\circ} \mathrm{C}$. The maximum temperatures for the 0.0101 and $0.0121 \mathrm{~kg} / \mathrm{s}$ air mass flow rates are reached 59.9 and $55.3{ }^{\circ} \mathrm{C}$, respectively, while the un-finned collector was 55

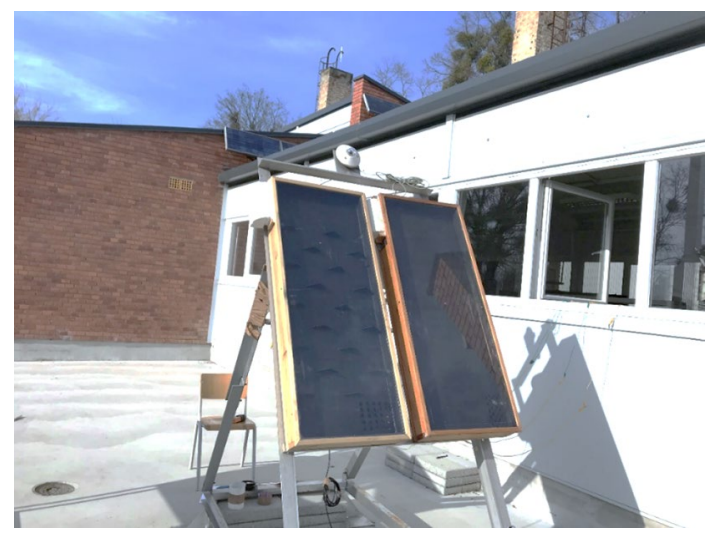

Fig. 4 Tested solar air collectors and $50.5{ }^{\circ} \mathrm{C}$, respectively. Moreover, the maximum temperature differences $\left(\Delta T=T_{0}-T_{\mathrm{i}}\right)$ increasing through the finned collector were $43.4,37.5$, and $32.5^{\circ} \mathrm{C}$, and for the un-finned collector were $38.5,32.6$, and $27.3{ }^{\circ} \mathrm{C}$ for $0.0081,0.0101$, and $0.0121 \mathrm{~kg} / \mathrm{s}$, respectively. Figure $5 \mathrm{~d}$ illustrates the airflow rate's effect on the temperature difference $(\Delta T)$, which has a reverse relation where $(\Delta T)$ decreased when the air mass flow rate increased. Thus, it is evidence of the importance of controlling the airflow rate to an optimum value to keep higher temperature variation through the collector to increase the heat gained and increase thermal efficiency.

Figure $6 a, b, c$ presents the variation of the absorber temperatures of the collectors versus time under each mass flow rate. It is seen clearly that the finned collector's absorbing surface temperature was less than the un-finned one. This reason was doubtless due to the increasing in heat transfer coefficients of the finned absorber to the circulated air in the upper channel of the collector. That is in line with previous research of Hassan and Abo-Elfadl, which reported that increasing the heat transfer rate with fins reduces the temperature of the absorber plate [12]. Chabane et al. stated that the presence of the fins on the absorbing surface made a good air distribution and took more heat energy from the bottom plate which makes the absorber temperature decrease [22]. According to [23], the presence of obstacles causes turbulent airflow within the collector, resulting in a higher heat transfer coefficient with lower absorber plate temperature while also reducing heat loss, resulting in improved thermal efficiency. Figure $6 \mathrm{~d}$ represent the average absorber temperature against the selected mass flow rate, where it shows clearly the difference in the absorber temperature of the collectors regardless of the air mass flow rates.

Figure 7 explains the relationship between the solar radiation and the collectors' useful energy with the time of the experiment under each mass flow rate. The amount of useful heat obtained is restricted by the airflow rate and the temperature differential between the outlet and inlet. Furthermore, the temperature difference between the inlet and outlet is greatly affected by solar radiation intensity. It is seen clearly in figures that the heat gain fluctuating line follows the solar radiation intensity where the solar radiation will increase to reach maximum value between 11:00 and 13:30. The useful energy increases with solar intensity until reaching a maximum value for the finned collector, which were $606.78,635.62$, and $637.8 \mathrm{~W} / \mathrm{m}^{2}$ respectively, while for the un-finned were $559.8,589.56$, and $592.46 \mathrm{~W} / \mathrm{m}^{2}$ for airflow rate $0.0081,0.0101$, and $0.0121 \mathrm{~kg} / \mathrm{s}$, respectively.

The instantaneous efficiency of the collectors versus the time of the experiment for each mass flow rate is shown in Fig. 8. The solar air collector efficiency $\eta$ is the most critical factor in deciding if the finned collector performs better than the un-finned one. Many parameters influence the solar collector efficiency, such as the solar radiation intensity, the 


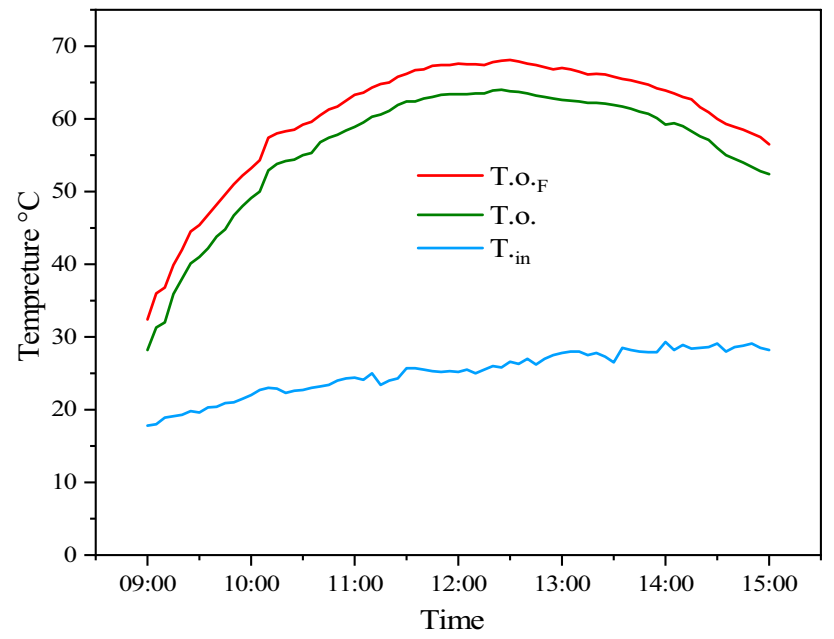

(a) at air mas flow rate $0.0081 \mathrm{~kg} / \mathrm{s}$

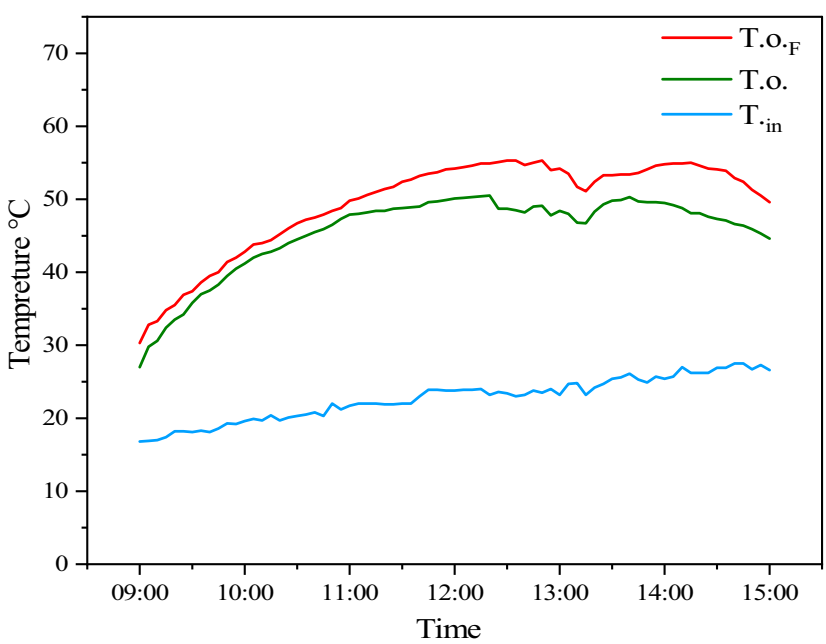

(c) at air mas flow rate $0.0121 \mathrm{~kg} / \mathrm{s}$

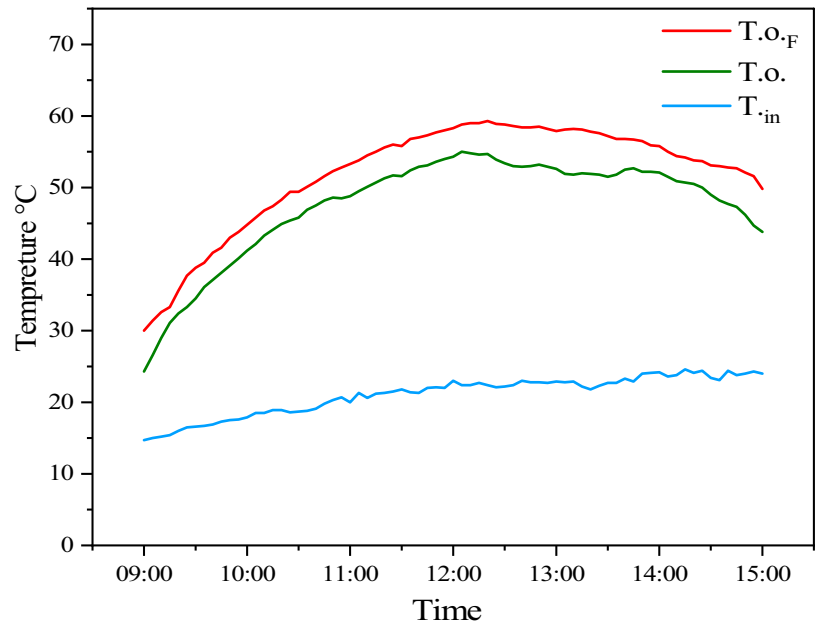

(b) at air mas flow rate $0.0101 \mathrm{~kg} / \mathrm{s}$

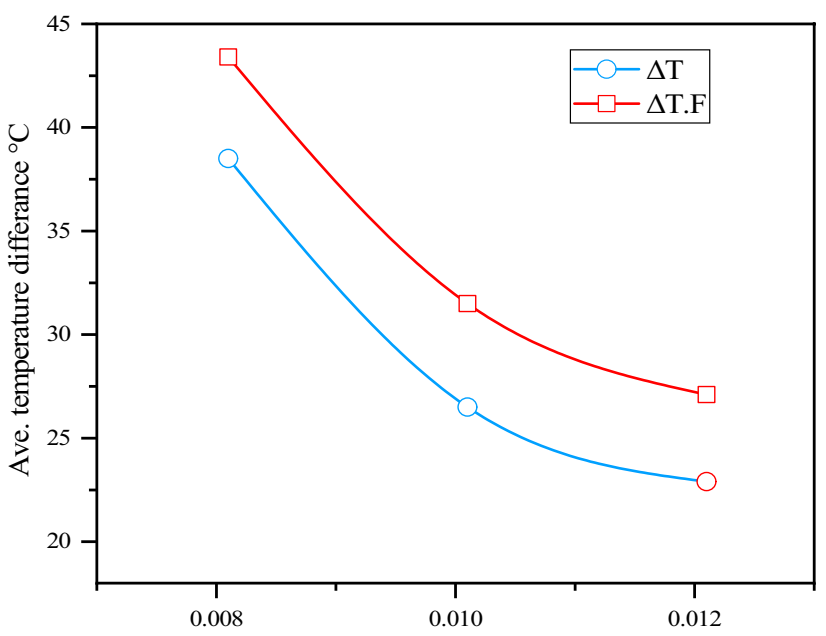

(d) mass flow rates $(\mathrm{kg} / \mathrm{s})$

Fig. $5 \mathbf{a}, \mathbf{b}, \mathbf{c}$ Inlet, outlet temperature of the collectors with time of experiment, $\mathbf{d}$ the average temperature difference $(\Delta T)$ versus different flow rates

heat losses from solar collector, wind speed, and ambient air temperature. It is observed that the thermal efficiency increased along with the increase of the useful heat energy gained. Moreover, from the outcomes, we derived that the presence of the fins played a significant factor in improving the collector efficiency due to the increases in the absorbing surface area, which enhances the internal thermal conductivity of the collector.

The instantaneous efficiency starts increasing to a maximum value between 11:00 am to the end of the experiments. Regardless of the mass flow rate, the finned collector is often more efficient than the un-finned one. The maximum instantaneous efficiencies obtained for the collectors without fins were $\eta 56.87 \%, 59.27$ and $63.16 \%$ and for the finned collector were $63.05 \%, 65.18 \%$, and $71.66 \%$ at mass flow rates $0.0081,0.0101$, and $0.0121 \mathrm{~kg} / \mathrm{s}$ respectively. The thermal efficiency of both collectors increased as the air mass flow increased, which is exactly what was stated in the literature. Chabane et al. reported that the thermal efficiency affected significantly by changing the mass flow rate and the shape of the absorber plate and the highest collector efficiency achieved by the finned collector [11]. Akpinar and Koçyiğit stated that collector efficiency depends significantly on solar radiation, absorber surface form, and airflow line extension. Moreover, the increasing in the air mass flow will enhance heat transfer coefficient and increase the collector efficiency [24]. Esen reported that the obstacles in the air channels are a critical factor in increasing collector efficiency [25].

Figure 9 presents the useful daily energy of the collectors under each mass flow rates. The daily efficiency used to estimate any collector performance can be determined by using the previously described trapezoidal method in Eq. 6 . 


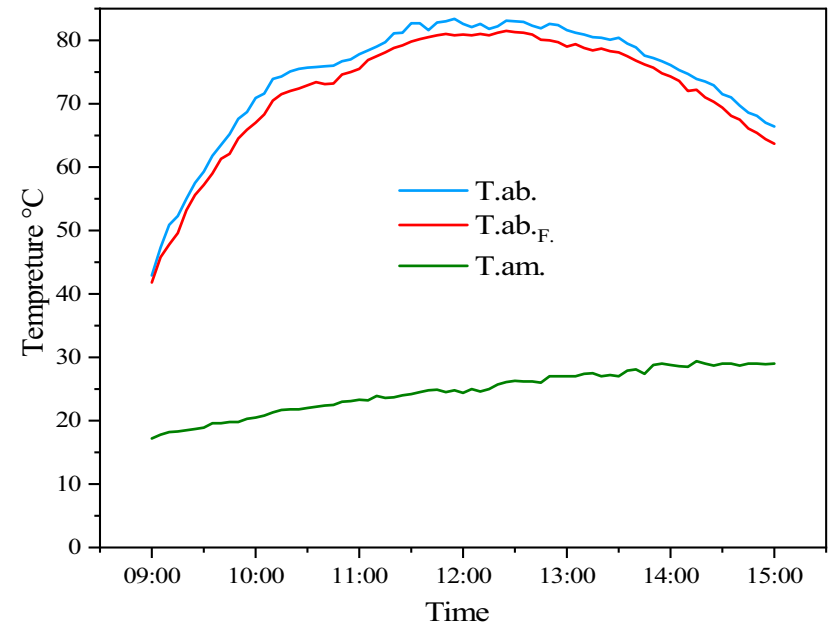

(a) at air mas flow rate $0.0081 \mathrm{~kg} / \mathrm{s}$

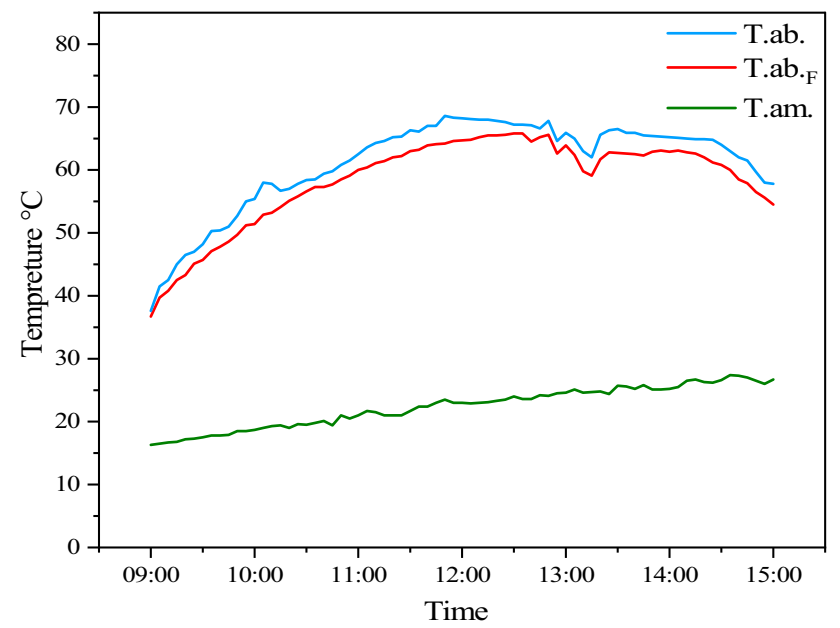

(c) at air mas flow rate $0.0121 \mathrm{~kg} / \mathrm{s}$

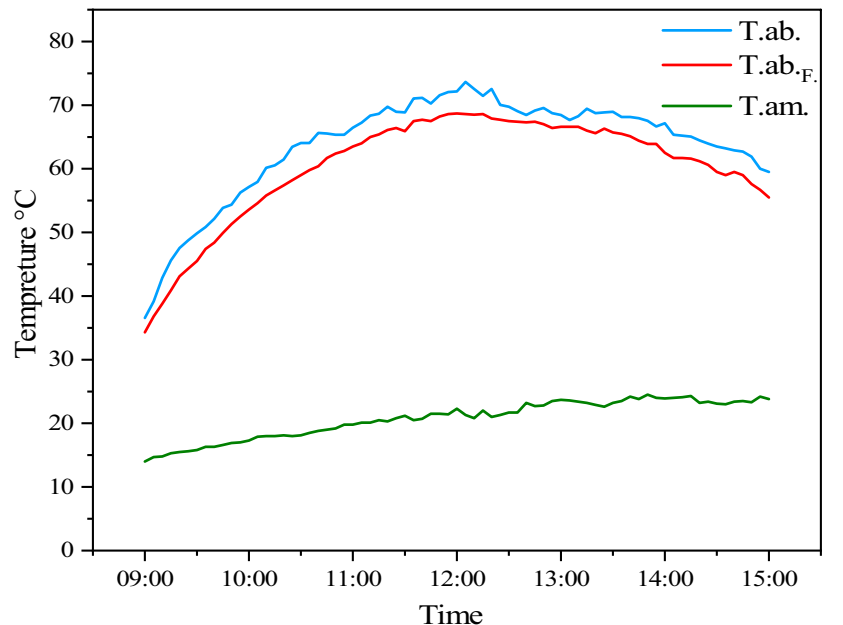

(b) at air mas flow rate $0.0101 \mathrm{~kg} / \mathrm{s}$

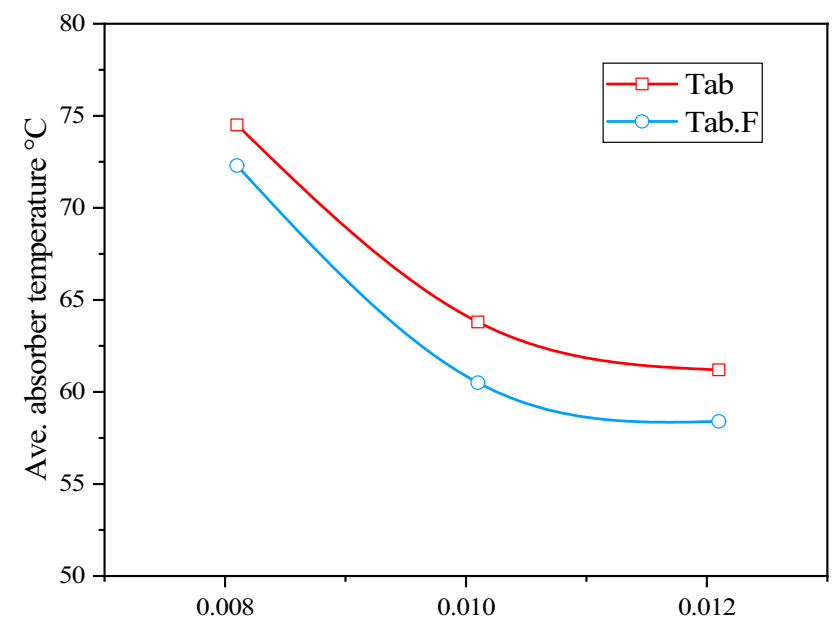

(d) mass flow rates $(\mathrm{kg} / \mathrm{s})$

Fig. $6 \mathbf{a}, \mathbf{b}$, and $\mathbf{c}$ instant absorber plate temperature of solar collectors with the ambient temperature versus time, $\mathbf{d}$ average absorber plate temperature versus different air flow rate

The collector daily efficiency improves as the airflow rate rises. The enhancement of the heat convective exchanges inside the collector explains that clearly. The daily thermal efficiencies of the finned collector were $56.57 \%, 59.41 \%$, and $61.42 \%$, while for the un-finned collector was $51.04 \%$, $53.28 \%$, and $57.08 \%$ for the air flow rates $0.0081,0.0101$, and $0.0121 \mathrm{~kg} / \mathrm{s}$, respectively. As a result, the finned collector showed real improvement of the collector efficiency about $4.3-6.1 \%$ over the un-finned one. Form the results we observed that the collector thermal efficiency depends significantly on the area of the absorbing surface.

Moreover, the presence of the obstacles will make an air flow turbulence which means that air will be in good contact with the absorbing plate and reaches all the areas and reduce the dead zones which increase the heat transfer coefficient. The figure shows that thermal efficiency improves as the air mass flow rate rises because of the heat transfer rate is directly proportional to the air mass flow rate. So, at a specified airflow rate, the presence of the fins increases the heat transfer surface area, which increases the heat transfer rate leading to greater thermal efficiency. That is agreed with what El-Sebaii et al. mentioned in their work which stated that thermal efficiency increases with rising mass flow rate until a typical value after which thermal efficiencies increase becomes insignificant. The slope of the efficiency will decrease while increasing the mass flow rate. That means, at higher mass flow rates, total heat losses are almost at their minimum value [5]. In the present work, the introduced design of the collector improved the efficiency with a high agreement compared to other works reported in the literature as illustrated in Table1. The present collector shows a higher performance when compared to the literature with taking into consideration the mass flow rate, which was $0.0121 \mathrm{~kg} / \mathrm{s}$. 


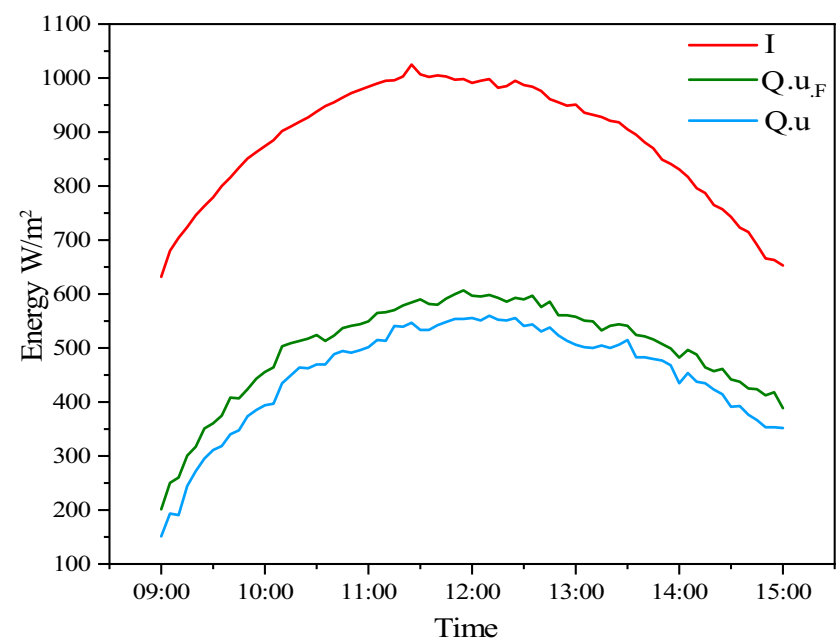

(a) at air mas flow rate $0.0081 \mathrm{~kg} / \mathrm{s}$

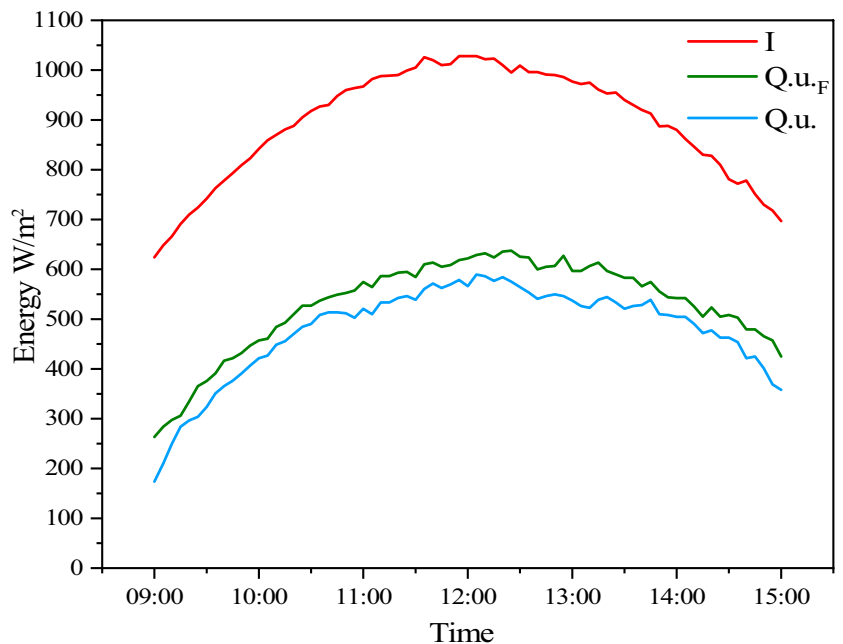

(b) at air mas flow rate $0.0101 \mathrm{~kg} / \mathrm{s}$

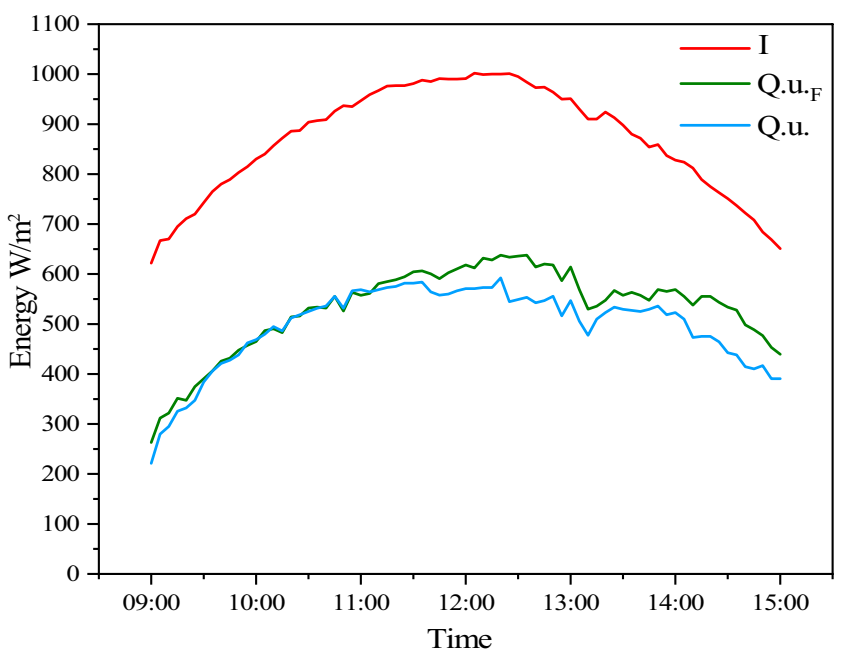

(c) at air mas flow rate $0.0121 \mathrm{~kg} / \mathrm{s}$

Fig. 7 Instantaneous useful heat gain, the solar radiation for the collectors under each mass flow rate

\section{Conclusions}

The performance of a two-pass solar air heater with and without triangular integrated fins was studied experimentally. The findings revealed that the outlet temperature is strongly influenced by solar radiation intensity and has an inverse relationship with air mass flow rate, which increases as the mass flow rate decrease and vice versa. The amount of the useful heat gain depends on the air flow rate and the change of the inlet air temperature, which causes an increase in thermal efficiency. The mass flow rate can be thought of as the primary parameter that controls, optimizes, and limits the amount of heat collected from the collector during the day as it has a direct effect on the temperature difference. The greater the temperature and radiation variation, the more beneficial heat gained. The maximum temperature difference increase through the finned collector was 43.4, 37.5, and $32.5^{\circ} \mathrm{C}$, while for the un-finned collector was $38.5,32.6$, and $27.3^{\circ} \mathrm{C}$ for $0.0081,0.0101$, and $0.0121 \mathrm{~kg} / \mathrm{s}$ respectively. Furthermore, independently of the mass flow rate, the efficiency of the finned collector is constantly higher than that of the un-finned one. The daily thermal efficiency of the finned collector was $56.57 \%$, 59.41\%, and $61.42 \%$, while for the un-finned collector was $51.04 \%, 53.28 \%$, and $57.08 \%$ for the air mass flow rates $0.0081,0.0101$, and $0.0121 \mathrm{~kg} / \mathrm{s}$. As a result, the finned solar air collector showed a 4.3-6.1\% increase in thermal efficiency over the un-finned one. The presence of the fins will make a turbulence airflow, which means the air will be in good contact with the absorber plate and reaches all the areas, and reduces the dead zones leading to an increase in the heat transfer. 


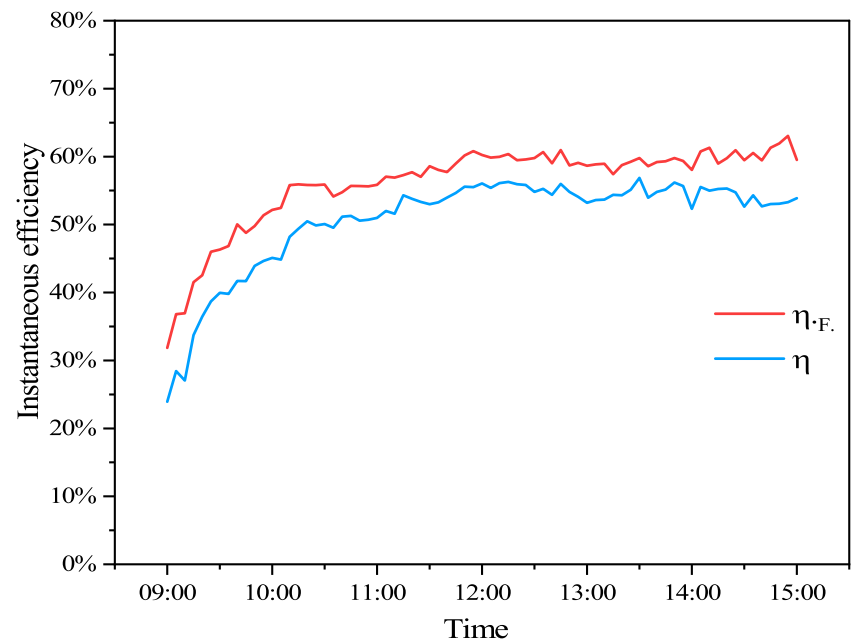

(a) at air mas flow rate $0.0081 \mathrm{~kg} / \mathrm{s}$

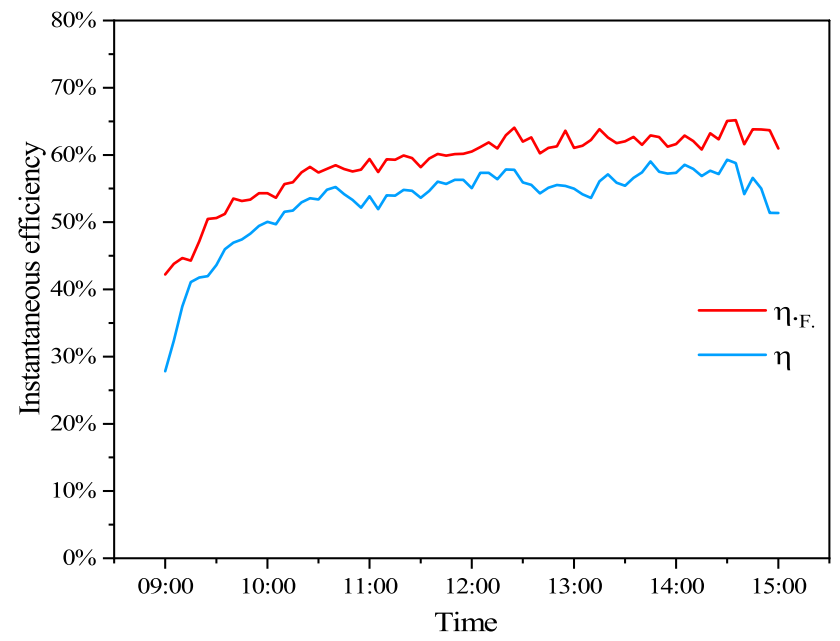

(b) at air mas flow rate $0.0101 \mathrm{~kg} / \mathrm{s}$

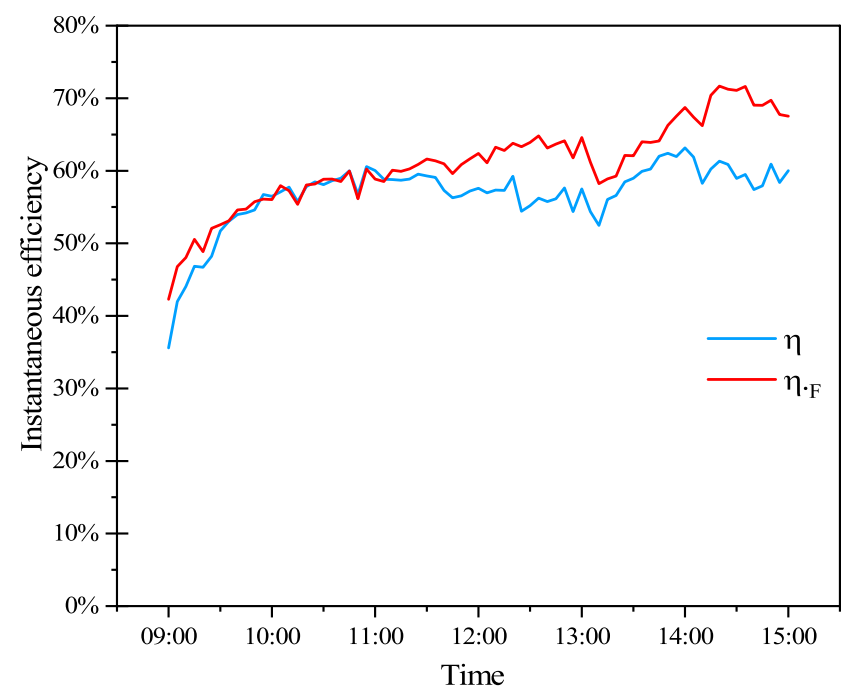

(c) at air mas flow rate $0.0121 \mathrm{~kg} / \mathrm{s}$

Fig. 8 Instantaneous efficiency of the collectors under each flow rate 


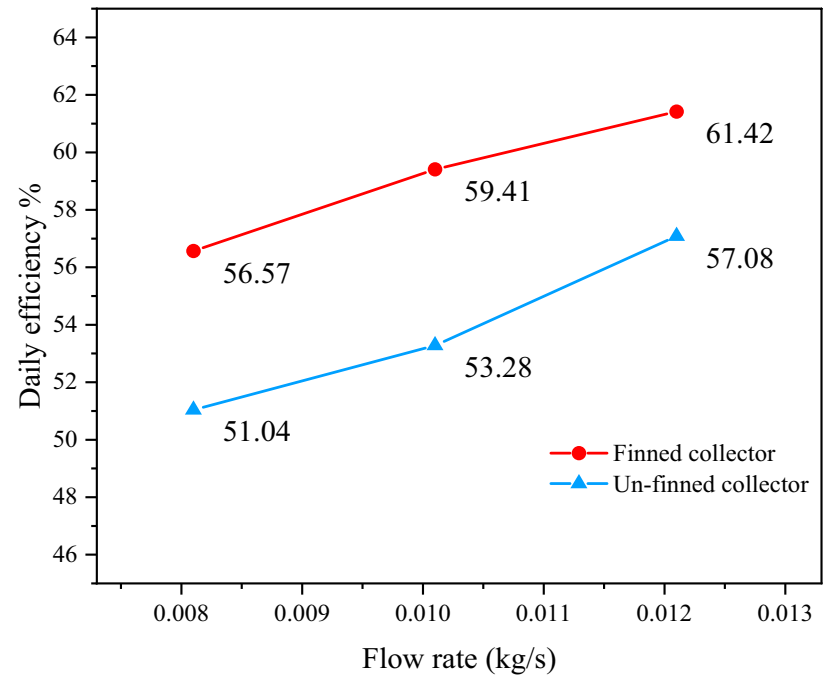

Fig. 9 Solar daily efficiency with mass flow rate

Acknowledgements This work was supported by the Stipendium Hungaricum Program and by the Doctoral School of Mechanical Engineering, Hungarian University of Agriculture and Life Sciences, Gödöllő, Hungary

Authors' contribution MM involved in conceptualization, methodology, investigation, data curation, software, writing original draft preparation; MA participated in investigation, data curation, draft preparation; JB involved in methodology, laboratory supervision, draft preparation; IF involved in conceptualization, methodology, reviewing and editing, supervision, funding acquisition.

Funding Open access funding provided by Hungarian University of Agriculture and Life Sciences.

Data availability The datasets analyzed during the current study are available from the corresponding author on reasonable request.

\section{Declarations}

Conflict of interest The authors declare that they have no known competing financial interests or personal relationships that could have appeared to influence the work reported in this paper.

Open Access This article is licensed under a Creative Commons Attribution 4.0 International License, which permits use, sharing, adaptation, distribution and reproduction in any medium or format, as long as you give appropriate credit to the original author(s) and the source, provide a link to the Creative Commons licence, and indicate if changes were made. The images or other third party material in this article are included in the article's Creative Commons licence, unless indicated otherwise in a credit line to the material. If material is not included in the article's Creative Commons licence and your intended use is not permitted by statutory regulation or exceeds the permitted use, you will need to obtain permission directly from the copyright holder. To view a copy of this licence, visit http://creativecommons.org/licenses/by/4.0/.

\section{References}

1. Tyagi, V.V., Panwar, N.L., Rahim, N.A., Kothari, R.: Review on solar air heating system with and without thermal energy storage system. Renew. Sustain. Energy Rev. 16, 2289-2303 (2012). https://doi.org/10.1016/j.rser.2011.12.005

2. Panwar, N.L., Kaushik, S.C., Kothari, S.: Role of renewable energy sources in environmental protection: A review. Renew. Sustain. Energy Rev. 15, 1513-1524 (2011). https://doi.org/10. 1016/j.rser.2010.11.037

3. Kalogirou, S.A.: Solar thermal collectors and applications. Prog. Energy Combust. Sci. 30, 231-295 (2004). https://doi.org/10. 1016/j.pecs.2004.02.001

4. Tchinda, R.: A review of the mathematical models for predicting solar air heaters systems. Renew. Sustain. Energy Rev. 13, 1734-1759 (2009). https://doi.org/10.1016/j.rser.2009.01.008

5. El-Sebaii, A.A., Aboul-Enein, S., Ramadan, M.R.I., Shalaby, S.M., Moharram, B.M.: Thermal performance investigation of double pass-finned plate solar air heater. Appl. Energy. 88, 17271739 (2011). https://doi.org/10.1016/j.apenergy.2010.11.017

6. Moummi, N., Youcef-Ali, S., Moummi, A., Desmons, J.Y.: Energy analysis of a solar air collector with rows of fins. Renew. Energy.

Table1 Demonstrates a comparison between the current work and others reported in the literature

\begin{tabular}{|c|c|c|c|}
\hline References & Research type & System description & Findings \\
\hline$[25]$ & Experimental & $\begin{array}{l}\text { Double pass air collector, Aluminum cans extended } \\
\text { surfaces }\end{array}$ & $\begin{array}{l}\text { The collector efficiency reached less about } 60 \% \text { at a } \\
\text { mass flow rate of } 0.05 \mathrm{~kg} / \mathrm{s}\end{array}$ \\
\hline$[10]$ & Experimental & $\begin{array}{l}\text { Single and double pass air collector, longitudinal fins } \\
\text { attached to the bottom side of a wired mesh absorber }\end{array}$ & $\begin{array}{l}\text { The collector daily efficiency was less than } 60 \% \text { for air } \\
\text { mass flow rate of } 0.038 \mathrm{~kg} / \mathrm{s}\end{array}$ \\
\hline$[5]$ & Both & $\begin{array}{l}\text { Double pass solar air heater, longitudinal fin attached } \\
\text { to the upper and lower side of the absorber plate }\end{array}$ & $\begin{array}{l}\text { The hourly efficiency } 55 \% \text { at mass flow rates } 0.04 \mathrm{~kg} / \mathrm{s} \\
\text { and less than } 50 \% \text { at mass flow rates below } 0.012 \mathrm{~kg} / \mathrm{s}\end{array}$ \\
\hline$[15]$ & Experimental & $\begin{array}{l}\text { Double pass air collector, V-groove absorber plate with } \\
\text { pin fins attached to the upper and lower sides of the } \\
\text { absorber }\end{array}$ & $\begin{array}{l}\text { The maximum obtained efficiency was } 52 \% \text { at mass flow } \\
\text { rate } 0.035 \mathrm{~kg} / \mathrm{s}\end{array}$ \\
\hline [13] & Experimental & $\begin{array}{l}\text { Double pass air collector, vertical and horizontal rec- } \\
\text { tangular fins in the upper channel }\end{array}$ & $\begin{array}{l}\text { The collector daily efficiency was } 56 \% \text { for air mass flow } \\
\text { rate of } 0.019 \mathrm{~kg} / \mathrm{s}\end{array}$ \\
\hline Present work & Experimental & $\begin{array}{l}\text { Double pass air collector, triangular integrated fins in } \\
\text { the upper channel }\end{array}$ & $\begin{array}{l}\text { The collector daily efficiency was more than } 61 \% \text { for air } \\
\text { mass flow rate of } 0.0121 \mathrm{~kg} / \mathrm{s}\end{array}$ \\
\hline
\end{tabular}


29, 2053-2064 (2004). https://doi.org/10.1016/j.renene.2003.11. 006

7. Karim, M.A., Hawlader, M.N.A.: Performance investigation of flat plate, v-corrugated and finned air collectors. Energy 31, 452-470 (2006). https://doi.org/10.1016/j.energy.2005.03.007

8. Sopian, K., Alghoul, M.A., Alfegi, E.M., Sulaiman, M.Y., Musa, E.A.: Evaluation of thermal efficiency of double-pass solar collector with porous-nonporous media. Renew. Energy. 34, 640-645 (2009). https://doi.org/10.1016/j.renene.2008.05.027

9. Fudholi, A., Ruslan, M.H., Othman, M.Y., Yahya, M., Supranto, Zaharim, A., Sopian, K.: Collector efficiency of the double-pass solar air collectors with fins. Int. Conf. Syst. Sci. Simul. Eng. Proc. 428-434 (2010)

10. Omojaro, A.P., Aldabbagh, L.B.Y.: Experimental performance of single and double pass solar air heater with fins and steel wire mesh as absorber. Appl. Energy. 87, 3759-3765 (2010). https:// doi.org/10.1016/j.apenergy.2010.06.020

11. Chabane, F., Moummi, N., Benramache, S., Bensahal, D., Belahssen, O.: Collector efficiency by single pass of solar air heaters with and without using fins. Eng. J. 17, 43-55 (2013). https://doi.org/ 10.4186/ej.2013.17.3.43

12. Hassan, H., Abo-Elfadl, S.: Experimental study on the performance of double pass and two inlet ports solar air heater (SAH) at different configurations of the absorber plate. Renew. Energy. 116, 728-740 (2018). https://doi.org/10.1016/j.renene.2017.09. 047

13. Al-Neama, M.A., Farkas, I.: Thermal efficiency of vertical and horizontal-finned solar collector integrated with forced air circulation dryer for Apple as a sample. Dry. Technol. 37, 546-558 (2019). https://doi.org/10.1080/07373937.2018.1488260

14. Mariana, S., Flores, S., Hernández, A.: 2013 ISES Solar World Congress thermal evaluation and modeling of a double-pass solar collector for air heating. Energy Procedia. 57, 2275-2284 (2014). https://doi.org/10.1016/j.egypro.2014.10.235

15. Sudhakar, P., Cheralathan, M.: Thermal performance enhancement of solar air collector using a novel V-groove absorber plate with pin-fins for drying agricultural products: an experimental study. J. Therm. Anal. Calorim. 140, 2397-2408 (2020). https:// doi.org/10.1007/s10973-019-08952-9

16. Velmurugan, P., Kalaivanan, R.: Thermal performance studies on multi-pass flat-plate solar air heater with longitudinal fins: An analytical approach. Arab. J. Sci. Eng. 40, 1141-1150 (2015). https://doi.org/10.1007/s13369-015-1573-5
17. Rai, S., Chand, P., Sharma, S.P.: An analytical investigations on thermal and thermohydraulic performance of offset finned absorber solar air heater. Sol. Energy. 153, 25-40 (2017). https:// doi.org/10.1016/j.solener.2017.05.039

18. Fudholi, A., Sopian, K., Ruslan, M.H., Othman, M.Y.: Performance and cost benefits analysis of double-pass solar collector with and without fins. Energy Convers. Manag. 76, 8-19 (2013). https://doi.org/10.1016/j.enconman.2013.07.015

19. Sahu, M.K., Prasad, R.K.: Exergy based performance evaluation of solar air heater with arc-shaped wire roughened absorber plate. Renew. Energy. 96, 233-243 (2016). https://doi.org/10.1016/j. renene.2016.04.083

20. Scheid, F.: Schaum's Outline of Theory and Problems of Numerical Analysis. McGraw-Hill, New York (1989)

21. Bekele, A., Mishra, M., Dutta, S.: Performance characteristics of solar air heater with surface mounted obstacles. Energy Convers. Manag. 85, 603-611 (2014). https://doi.org/10.1016/j.enconman. 2014.04.079

22. Chabane, F., Hatraf, N., Moummi, N.: Experimental study of heat transfer coefficient with rectangular baffle fin of solar air heater. Front. Energy. 8, 160-172 (2014). https://doi.org/10.1007/ s11708-014-0321-y

23. Karsli, S.: Performance analysis of new-design solar air collectors for drying applications. Renew. Energy. 32, 1645-1660 (2007). https://doi.org/10.1016/j.renene.2006.08.005

24. Akpinar, E.K., Koçyiğit, F., Koçyiğit, F.: Experimental investigation of thermal performance of solar air heater having different obstacles on absorber plates. Int. Commun. Heat Mass Transf. 37, 416-421 (2010). https://doi.org/10.1016/j.icheatmasstransfer. 2009.11.007

25. Esen, H.: Experimental energy and exergy analysis of a doubleflow solar air heater having different obstacles on absorber plates. Build. Environ. 43, 1046-1054 (2008). https://doi.org/10.1016/j. buildenv.2007.02.016

Publisher's Note Springer Nature remains neutral with regard to jurisdictional claims in published maps and institutional affiliations. 